NBER WORKING PAPER SERIES

\title{
DIVERSIFICATION AND THE TAXATION OF CAPITAL GAINS AND LOSSES
}

\author{
Richard J. Rendleman, Jr. \\ Douglas A. Shackelford \\ Working Paper 9674 \\ http://www.nber.org/papers/w9674 \\ NATIONAL BUREAU OF ECONOMIC RESEARCH
1050 Massachusetts Avenue
Cambridge, MA 02138
}

May 2003

The authors appreciate comments by workshop participants at Lancaster University, Tilburg University and research assistance by Courtney Edwards. In addition, the comments of Leonce Bargeron, Robert Bushman, Zhonglan Dai, Ted Day, Alex Deshkovski, Bin Gao, Kushal Kshirsagar, Bradley Lindsey, Ed Maydew, Mehmet Orhan, Irina Stefanescu, Wendy Wilson and Harold Zhang are gratefully acknowledged. The views expressed herein are those of the authors and not necessarily those of the National Bureau of Economic Research.

(C2003 by Richard J. Rendleman, Jr. and Douglas A. Shackelford. All rights reserved. Short sections of text not to exceed two paragraphs, may be quoted without explicit permission provided that full credit including Cnotice, is given to the source. 
Diversification and the Taxation of Capital Gains and Losses

Richard J. Rendleman, Jr. and Douglas A. Shackelford

NBER Working Paper No. 9674

May 2003

JEL No. H2, G12, G13

\section{$\underline{\text { ABSTRACT }}$}

Current U.S. law nets the total portfolio of realized capital gains and losses to compute capital gains taxes. Prior research, however, typically ignores the implication of this provision, i.e., the marginal tax rate for a specific gain or loss depends on the taxpayer's total portfolio of realized gains and losses. We find that these nettings introduce complexity into the relation between share values and capital gains taxes, creating an incentive to diversify. For firms with stock returns that are positively (negatively) correlated with those of the overall market, share values generally are decreasing (increasing) in the capital gains tax rate.

Richard J. Rendleman, Jr.

Kenan-Flager Business School

University of North Carolina at Chapel Hill

Chapel Hill, NC 27599-3490

richard_rendleman@unc.edu
Douglas A. Shackelford

Kenan-Flager Business School

University of North Carolina at Chapel Hill

Chapel Hill, NC 27599-3490

and NBER

douglas_shackelford@unc.edu 


\section{Diversification and the Taxation of Capital Gains and Losses}

This paper explores the incentives to hold a diversified portfolio that arise from the asymmetric tax treatment of capital gains and losses. Under current U.S. law, the total portfolio of realized capital gains is netted annually against the total portfolio of realized capital losses. ${ }^{1}$ If gains exceed losses, the net gain is taxed. If losses exceed gains, individuals can deduct $\$ 3,000$ of the net loss. Losses that are not deducted in the year of realization are carried forward indefinitely, offsetting gains in future years. ${ }^{2}$

Prior analyses of capital gains taxes typically ignore the provisions governing the pooling of gains and losses. ${ }^{3}$ Their impact is assumed minor, and modeling them is an analytical challenge. This paper develops a model which employs the mathematics of option pricing theory to evaluate the impact of the current capital gains tax system on common stock valuations. We find that these nettings introduce complexity into the basic relation between share values and capital gains taxes. For firms with stock returns that are positively correlated with those of the overall market, share values generally are a decreasing function of the capital gains tax rate. However, for firms whose stock returns are negatively correlated with the overall market, share values generally increase with the capital gains tax rate.

This counterintuitive result - shareholder taxes enhance share value - occurs because taxpayers can expect to offset taxable capital gains in an overall portfolio with a capital loss from an individual stock if the returns of the stock and portfolio are negatively correlated. In such a situation, the effective capital gains tax rate associated with the stock is negative. Similarly, if the overall portfolio incurs a realized capital loss, the expected capital gains tax on a stock whose returns are negatively correlated with those of the portfolio is zero, since the expected gain on the stock should be offset by a capital loss in the portfolio. Therefore, on balance, the expected effective capital gains tax rate for a stock whose returns are negatively correlated with those of the investor's overall portfolio is negative. Consequently, the current U.S. tax system provides

\footnotetext{
${ }^{1}$ For individual taxpayers, further complexities arise from the dichotomization of gains and losses into short-term and long-term. Throughout this paper, we ignore these holding period distinctions without loss of generality.

${ }^{2}$ If losses exceed gains for corporations, no deduction is permitted currently. Instead the net realized loss is carried back and deducted against net capital gains for the previous three years. Any remaining loss offsets net capital gains in the subsequent five years, after which period it expires unutilized.

${ }^{3}$ Extant capital gains tax studies include Constantinides (1983, 1984), Stiglitz (1983), Poterba (1987), Landsman and Shackelford (1995), Erickson (1998), Reese (1998), Guenther and Willenborg (1999), Klein (1999), Poterba and Weisbenner (2001), Shackelford and Verrecchia (2002), Ayers, et. al (2003), and Blouin, et al. (2003), among many others.
} 
an incentive to hold investments with returns that provide negative correlation with market returns.

This paper makes three primary contributions. First, it advances the ongoing research investigating the effects of capital gains taxes on equity prices (see reviews in Graham [2003] and Shackelford and Shevlin [2001]) by showing that the pooling of capital gains and losses can affect individual common stock valuations. More generally, it contributes to research that investigates the economic implications of asymmetric tax treatment of gains and losses. For example, when gains create immediate taxes, but losses do not necessarily create immediate refunds, hedging is encouraged (Graham and Smith [1999]), but not entrepreneurship (Gentry and Hubbard [2001]).

Second, by evaluating a setting where the effective marginal tax rate depends on other aspects of the taxpayer's opportunity set, the paper provides a framework that can be applied more generally, because the tax considerations of all decisions are conditional on an investor's other taxable activities. To give an example from a different setting, the U.S. corporate income tax rate that applies to dividends from a foreign corporation depends on a firm's repatriations from all other foreign subsidiaries.

Third, the paper is timely for current policy debates. In recent years researchers could ignore the netting of capital gains and losses because the long-running bull market in the 1980s and 1990s, preceded by inflation in the 1970s (recall taxes are assessed on nominal, not real, profits), generally rendered the treatment of capital losses irrelevant since gains far exceeded losses for most investors. ${ }^{4}$ The downturn in the markets since 2000 has left many investors facing substantial capital losses. Congress has been considering legislation that would increase the $\$ 3000$ net capital loss limit for individuals (which has remained unchanged since 1977). Any such increase would mitigate, but not fundamentally alter, the complex incentives arising under the current structure. By explicitly modeling these incentives, this paper may be instructive in the evaluation of new policy.

\footnotetext{
${ }^{4}$ As evidence, the Internal Revenue Service [1999a, 1999b] reports that in 1997 individuals in the maximum tax bracket (39.6 percent), who accounted for 61 percent of all net capital gains, reported \$169 billion of long-term capital gains and only $\$ 5$ billion of long-term capital losses and $\$ 16$ billion of short-term capital gains and only $\$ 8$ billion of short-term capital losses. In addition, Poterba [1987] and Auerbach, Burman and Siegel [2000] found the $\$ 3000$ limit for individuals on currently deductible capital losses seldom binding.
} 
The remainder of this paper is organized as follows. Section I models a stock's value in light of the current capital loss limitations in the U.S. tax. Section II examines the mathematical properties of the model, and section III provides concluding remarks.

\section{The Model}

\section{A. Initial Conditions}

This section derives a stock's equilibrium value when its capital gains and losses are subject to a tax system that fully taxes net capital gains (total portfolio gains in excess of losses), but provides no deduction for net capital losses (total portfolio losses in excess of gains). ${ }^{5}$ The principal finding is that this tax structure generally causes a firm's stock value to be decreasing (increasing) in the capital gains tax rate if its returns are positively (negatively) correlated with the returns of the market portfolio of assets whose realized returns are subject to capital gains taxation. Intuitively, positive correlation reduces the probability that the stock and the portfolio will move inversely and thus benefit from the pooling of gains and losses. Other relevant factors in the model include the rate of dividend growth for the stock and the portfolio, the level of interest rates, and the extent of risk aversion in the pricing of financial assets.

Assume the price of a stock, $S_{0}$, reflects the expectation that the stock and the portfolio of which it is a part will be sold every $m$ years. ${ }^{6}$ The sale will trigger a capital gain or loss taxed at a rate of $\tau_{g}$. No distinction is made between long-term and short-term capital gains and losses, i.e., both are taxed at the same rate. The stock pays a continuous dividend that starts at an annual rate of $d i v_{S}$ dollars and is expected to grow at an annual rate of $g_{S}$. Dividends are taxed at a rate of $\tau_{d}$. Both $\tau_{g}$ and $\tau_{d}$ are assumed to remain constant.

\footnotetext{
${ }^{5}$ For tractability, we assume that losses, which are not deductible in the year of realization, are never deducted. This assumption overstates the costs of loss limitations under the current U.S. federal tax system, which permits carryover of losses. However, since the time value of money reduces the benefit of a deferred deduction during periods of constant or falling tax rates, this omission does not affect the generality of our principal results. ${ }^{6}$ Unlike Constantinedes [1983], our model of equity valuation does not reflect the possibility of optimal timing of capital gain and loss recognition. We recognize that timing of capital gains and losses plays a significant role in equity valuation. Nevertheless, our simpler approach allows us to focus on the valuation effects of the limitation on the deduction of capital losses and the netting of realized portfolio gains and losses in the computation of the capital gains tax. However, at least for some investors, this assumption is likely descriptive. For example, an individual may invest through mutual funds that generate capital gains over which he has no discretion. If so, he may evaluate individual stocks in light of the capital gains flowing from the fund, an analytical approach analogous to the one employed in this paper .
} 
At any time $t$, the expected annual rate of after-tax dividend payment is $d i v_{S}\left(1-\tau_{d}\right) e^{g_{S} t}$, and the actual after-tax dividend received over an infinitesimally small time interval $d t$ is $d i v_{S}\left(1-\tau_{d}\right) e^{g_{S} t} d t$. The discount rate applicable to the after-tax dividend is $k_{S}$, with $k_{S}>g_{S}$, and reflects the uncertainty of the dividend stream. Thus, the present value of the after-tax dividend paid over the time interval $d t$ is $d i v_{S}\left(1-\tau_{d}\right) e^{\left(g_{S}-k_{S}\right) t} d t$, and the present value of after-tax dividends paid between time $t=0$ and time $t=m$ is:

$$
\begin{aligned}
\int_{0}^{m} \operatorname{div}_{S}\left(1-\tau_{d}\right) e^{\left(g_{S}-k_{S}\right) t} d t & =\operatorname{div}_{S}\left(1-\tau_{d}\right)\left(\frac{1-e^{\left(g_{S}-k_{S}\right) m}}{k_{S}-g_{S}}\right) \\
& =\operatorname{gordon}_{S}\left(1-e^{\left(g_{S}-k_{S}\right) m}\right)
\end{aligned}
$$

where $\operatorname{gordon}_{S}=\frac{d i v_{S}\left(1-\tau_{d}\right)}{k_{S}-g_{S}}$, the value of the stock as given by the standard Gordon growth model..$^{7}$ To simplify the notation and exposition, $\int_{0}^{m} d i v_{S}\left(1-\tau_{d}\right) e^{\left(g_{S}-k_{S}\right) t} d t$ is denoted as $P V D_{S}(0, m)$, where $P V D_{S}(a, b)=\int_{a}^{b} d i v_{S}\left(1-\tau_{d}\right) e^{g_{S} t-k_{S}(t-a)} d t$ and represents the present value, as of time $a$, of the dividends to be received between times $a$ and $b$.

An investor who purchases the stock at time $t=0$ would expect to obtain value of $P V D_{S}(0, m)$ (i.e., the after-tax present value of dividends paid between time $t=0$ and time $t=m$ ) plus the present value of the after-tax proceeds from selling the stock at time $m$. For the purposes of valuing the stock, it is useful to express the initial stock price as a multiple of $P V D_{S}(0, m)$ such that $S_{0}=\phi_{S} P V D_{S}(0, m) .^{8}$

Since the rate of growth in dividends is assumed to remain constant, $E\left(S_{m}\right)$, the expected stock price at time $m$, should bear the same relationship to the present value, as of time $m$, of the after-tax dividends expected between times $m$ and $2 m$ as the price at time 0 bears to the

\footnotetext{
${ }^{7}$ The Gordon model assumes that dividends grow at a constant rate of $g_{s}$ forever and that the dividend stream is discounted at a constant rate, $k_{s}$, with $k_{s}>g_{s}$.
} 
present value of after-tax dividends between times 0 and $m$. Thus, $E\left(S_{m}\right)=\phi_{S} E(P V D[m, 2 m])=\phi_{S} P V D_{S}(0, m) e^{g_{S} m}$

\section{B. Determining the Valuation Impact of Capital Gains and Losses}

The key to understanding the impact of capital gains taxation in the pricing of the stock is recognizing that the full value of a stock's realized gain or loss is included in taxable income if and only if the realized capital gains of the investor's portfolio exceed the total of capital losses. Let $B_{S}$ denote the investor's basis in the stock, $\widetilde{Q}_{m}$ denote the aggregate proceeds from the sale of total portfolio assets at time $m$, and $B_{Q}$ represent the sum of the tax bases of the total portfolio. Then, the net taxable capital gain or loss from the proceeds of selling the stock at time $m$ at a price of $\widetilde{S}_{m}$ is $\left(\widetilde{S}_{m}-B_{S}\right) \mid \widetilde{Q}_{m}>B_{Q} \cdot{ }^{9} \quad$ (In our model we assume that $\widetilde{S}_{m}-B_{S}$ is sufficiently small that it can be ignored in determining whether $\widetilde{Q}_{m}>B_{Q} \cdot{ }^{10}$ ) The initial stock value, $S_{0}$, can then be expressed as follows:

$$
\begin{aligned}
S_{0} & =\phi_{S} P V D_{S}(0, m) \\
& =P V D_{S}(0, m)+\phi_{S} P V D_{S}(0, m) e^{\left(g_{S}-k_{S}\right) m}-\tau_{g} P V\left(\left[\widetilde{S}_{m}-B_{S}\right] \mid \widetilde{Q}_{m}>B_{Q}\right),
\end{aligned}
$$

where $P V(\bullet)$ denotes the present value operator. In equation $(2), P V D_{S}(0, m)$ is the present value of after-tax dividends to be received between times $t=0$ and $t=m$.

$\phi_{S} P V D_{S}(0, m) e^{\left(g_{S}-k_{S}\right) m}$ is the expected stock price at time $m$ discounted to the present at the rate $k_{S} \cdot \tau_{g} P V\left(\left[\widetilde{S}_{m}-B_{S}\right] \mid \widetilde{Q}_{m}>B_{Q}\right)$ is the present value of the incremental capital gains tax

\footnotetext{
${ }^{8}$ The use of the dividend multiple, $\phi_{S}$, enables one to infer the mathematics of the stock's valuation between times $m$ and $\infty$ from the valuation between times 0 and $m$. As such, it significantly simplifies the mathematics of valuation, although $\phi_{S}$ itself plays no direct role in the economics of the model.

${ }^{9}$ In other words, if $\tilde{Q}_{m}>B_{Q}$ and $\tilde{S}_{m}>B_{S}$, then the investor must pay $\tau_{g}\left(\tilde{S}_{m}-B_{S}\right)$ in additional capital gains taxes. If $\tilde{Q}_{m}>B_{Q}$ and $\tilde{S}_{m}<B_{S}$, then the investor's capital gains tax liability is reduced by $\tau_{g}\left(\tilde{S}_{m}-B_{S}\right)$. If $\tilde{Q}_{m}<B_{Q}$ and $\tilde{S}_{m}>B_{S}$, the individual stock's capital gain of $\tilde{S}_{m}-B_{S}$ escapes taxation. If $\tilde{Q}_{m}<B_{Q}$ and $\tilde{S}_{m}<B_{S}$, then the individual stock's capital loss of $\tilde{S}_{m}-B_{S}$ simply increases the investor's supply of nondeductible capital losses and thus produces no tax savings.
} 
expected to be paid from the sale of the stock at time $m$, conditional upon the value of the portfolio exceeding its tax basis $\left(\widetilde{Q}_{m}>B_{Q}\right)$.

Since the tax basis is equal to the stock value at the time of purchase, an investor who buys the stock at a price of $S_{0}$ will establish a basis of $S_{0}$, i.e., $B_{S}=S_{0}$. Accordingly, $P V\left(\left[\widetilde{S}_{m}-B_{S}\right] \mid \widetilde{Q}_{m}>B_{Q}\right)=P V\left(\left[\widetilde{S}_{m}-S_{0}\right] \mid \widetilde{Q}_{m}>B_{Q}\right)$, which, in turn, can be expressed as $P V\left(\widetilde{S}_{m} \mid \widetilde{Q}_{m}>B_{Q}\right)-P V\left(S_{0} \mid \widetilde{Q}_{m}>B_{Q}\right)$. To evaluate these expressions, we assume $\widetilde{S}_{m}$ and $\widetilde{Q}_{m}$ are jointly lognormal with $E\left(\ln \left[\widetilde{S}_{m} / S_{0}\right]\right)=m \mu_{S}, E\left(\ln \left[\widetilde{Q}_{m} / Q_{0}\right]\right)=m \mu_{Q}$, $\operatorname{var}\left(\ln \left[\widetilde{S}_{m} / S_{0}\right]\right)=m \sigma_{S}^{2}, \operatorname{var}\left(\ln \left[\widetilde{Q}_{m} / Q_{0}\right]\right)=m \sigma_{Q}^{2}$ and correlation $\rho$. Following Rubinstein (1976, p. 419), we first compute the conditional expectation

$$
\begin{aligned}
E\left(\widetilde{S}_{m} \mid Q_{m}>B_{Q}\right) & =S_{0} e^{-y_{S} m} \int_{-\infty}^{\infty} \int_{c}^{\infty} e^{r_{S} m} f\left(r_{Q}, r_{S}\right) d r_{Q} d r_{S} \\
& =S_{0} e^{\left(\mu_{S}+\frac{1}{2} \sigma_{S}^{2}-y_{S}\right) m} N(z 1) \\
z 1 & =\frac{-c+\left(\mu_{Q}-y_{Q}+\rho \sigma_{Q} \sigma_{S}\right) m}{\sigma_{Q} \sqrt{m}} ; \quad c=\ln \left(\frac{B_{Q}}{Q_{0}}\right),
\end{aligned}
$$

where $r_{S}$ and $r_{Q}$ are the logarithmic stock and portfolio returns, respectively, with means $\mu_{S}$ and $\mu_{Q}$ and variances $\sigma_{S}^{2}$ and $\sigma_{Q}^{2}$ per unit of time. $f\left(r_{Q}, r_{S}\right)$ is the joint lognormal density function in standardized form, $y_{S}$ and $y_{Q}$ are the annualized dividend yields for the stock and portfolio, respectively, and $N(z)$ is the area under the standard normal density function from $-\infty$ to $\mathrm{z}^{11}$ Also, following Rubinstein [1976, p. 419],

\footnotetext{
${ }^{10}$ If we did not assume that $\tilde{S}_{m}-B_{S}$ was sufficiently small, the condition would be $\tilde{Y}_{m}+\tilde{S}_{m}>B_{Y}+B_{S}$, where $Y=Q-S$, which identifies all investments other than $S$.

${ }^{11}$ Rubinstein (1976) does not include dividends in the formulation of conditional expected values. Nevertheless, using standard option pricing theory, the inclusion of dividends is straightforward.
} 


$$
\begin{aligned}
E\left(S_{0} \mid \widetilde{Q}_{m}>B_{Q}\right) & =S_{0} \int_{c}^{\infty} f\left(r_{Q}\right) d r_{Q} \\
& =S_{0} N(z 2) \\
z 2 & =\frac{-c+\left(\mu_{Q}-y_{Q}\right) m}{\sigma_{Q} \sqrt{m}} ; \quad c=\ln \left(\frac{B_{Q}}{Q_{0}}\right)
\end{aligned}
$$

where $f\left(r_{Q}\right)$ is the univariate lognormal density function in standardized form.

To obtain present values, we apply standard risk-neutral valuation methodology to the expected values from equations (3) and (4). ${ }^{12}$ Using this methodology, we first equate the expected instantaneous returns for the stock and the portfolio to the risk-free interest rate, $r$, resulting in $\mu_{S}+\frac{1}{2} \sigma_{S}^{2}=r$ for the stock and $\mu_{Q}+\frac{1}{2} \sigma_{Q}^{2}=r$ for the portfolio. Next, we equate the two components of the expected net capital gain to the risk-free rate by substituting $\mu_{S}+\frac{1}{2} \sigma_{S}^{2}=r$ and $\mu_{Q}+\frac{1}{2} \sigma_{Q}^{2}=r$ into equations (3) and (4) and discounting both conditional expected values at the risk-free interest rate.

$$
\begin{aligned}
P V\left(\widetilde{S}_{m} \mid \widetilde{Q}_{m}>B_{Q}\right) & =E\left(\widetilde{S}_{m} \mid \widetilde{Q}_{m}>B_{Q}\right) e^{-r m} \\
& =S_{0} e^{-y_{S} m} N(z 1) \\
z 1 & =\frac{\ln \left(Q_{0} / B_{Q}\right)+\left(r-y_{Q}-\frac{1}{2} \sigma_{Q}^{2}+\rho \sigma_{Q} \sigma_{S}\right) m}{\sigma_{Q} \sqrt{m}}, \text { and }
\end{aligned}
$$

\footnotetext{
${ }^{12}$ Stulz (1982), in valuing an option on the minimum or maximum value of two risky assets, also applies risk-neutral valuation methodology to a problem identical in structure, except for terminal values or boundary conditions.
} 


$$
\begin{aligned}
P V\left(S_{0} \mid \widetilde{Q}_{m}>B_{Q}\right) & =E\left(S_{0} \mid \widetilde{Q}_{m}>B_{Q}\right) e^{-r m} \\
& =S_{0} e^{-r m} N(z 2) \\
z 2 & =\frac{\ln \left(Q_{0} / B_{Q}\right)+\left(r-y_{Q}-\frac{1}{2} \sigma_{Q}^{2}\right) m}{\sigma_{Q} \sqrt{m}} .
\end{aligned}
$$

Combining terms,

$$
\begin{gathered}
P V\left(\widetilde{S}_{m}-S_{0} \mid \widetilde{Q}_{m}>B_{Q}\right)=S_{0}\left(e^{-y_{S} m} N[z 1]-e^{-r m} N[z 2]\right) \\
z 1=\frac{\ln \left(Q_{0} / B_{Q}\right)+\left(r-y_{Q}-\frac{1}{2} \sigma_{Q}^{2}+\rho \sigma_{Q} \sigma_{S}\right) m}{\sigma_{Q} \sqrt{m}} ; \quad z 2=\frac{\ln \left(Q_{0} / B_{Q}\right)+\left(r-y_{Q}-\frac{1}{2} \sigma_{Q}^{2}\right) m}{\sigma_{Q} \sqrt{m}} .
\end{gathered}
$$

\section{Determining the Equilibrium Values of the Portfolio and Stock}

Thus far we have placed no restriction on portfolio $Q$. It is simply a portfolio held by an investor that is expected to be sold every $m$ years. However, for the purposes of determining the equilibrium stock price, we assume that portfolio $Q$ represents the market portfolio of all assets subject to capital gains taxation and like the stock, its value reflects the expectation that all of its component assets will be sold every $m$ years.

Since the equilibrium value of any stock is a function of the value of this market portfolio, we must first determine the portfolio's equilibrium value. As in the valuation of the stock, we assume the portfolio's value reflects the expectation of lognormal returns and a constant rate of growth in dividends. Therefore, the mathematics of the portfolio's valuation is the same as for the valuation of the stock. Substituting $Q$ for $S$ in equation (2), the value of the market portfolio becomes:

$$
\begin{aligned}
Q_{0} & =\phi_{Q} P V D_{Q}(0, m) \\
& =P V D_{Q}(0, m)+\phi_{Q} P V D_{Q}(0, m) e^{\left(g_{Q}-k_{Q}\right) m}-\tau_{g} P V\left(\left[\widetilde{Q}_{m}-B_{Q}\right] \mid \widetilde{Q}_{m}>B_{Q}\right) .
\end{aligned}
$$

As with an individual stock, we assume that the initial purchase price of the portfolio establishes its tax basis. Therefore, in deriving the equilibrium value of the market portfolio, we set $B_{Q}=Q_{0}^{*}$, where $Q_{0}^{*}=\phi_{Q}^{*} P V D_{Q}(0, m)$ denotes the portfolio's equilibrium value. Making this 
substitution into equation (8) and expressing the initial portfolio value as an equilibrium value gives:

$$
\begin{aligned}
Q_{0}^{*} & =\phi_{Q}^{*} P V D_{Q}(0, m) \\
& =P V D_{Q}(0, m)+\phi_{Q}^{*} P V D_{Q}(0, m) e^{\left(g_{Q}-k_{Q}\right) m}-\tau_{g} P V\left(\left[\widetilde{Q}_{m}-Q_{0}^{*}\right] \mid \widetilde{Q}_{m}>Q_{0}^{*}\right) .
\end{aligned}
$$

The term $P V\left(\left[\widetilde{Q}_{m}-Q_{0}^{*}\right] \mid \widetilde{Q}_{m}>Q_{0}^{*}\right)$ in equation (9) is evaluated by substituting $\rho=1$

(since the market portfolio is perfectly correlated with itself), $\sigma_{S}=\sigma_{Q}$ and $y_{S}=y_{Q}^{*}$ into equation (7). The substitution $y_{S}=y_{Q}^{*}$ reflects that the portfolio's equilibrium dividend yield will be a function of its initial equilibrium value. With these substitutions, and the evaluation of $P V\left(\left[\widetilde{Q}_{m}-Q_{0}^{*}\right] \mid \widetilde{Q}_{m}>Q_{0}^{*}\right)$ under the assumption of lognormal portfolio returns, the equilibrium value of the market portfolio becomes:

$$
\begin{aligned}
Q_{0}^{*} & =\phi_{Q}^{*} P V D_{Q}(0, m) \\
& =P V D_{Q}(0, m)+\phi_{Q}^{*} P V D_{Q}(0, m) e^{\left(g_{Q}-k_{Q}\right)^{m}}-\tau_{g} P V\left(\left[\widetilde{Q}_{m}-Q_{0}^{*}\right] \mid \widetilde{Q}_{m}>Q_{0}^{*}\right) \\
& =P V D_{Q}(0, m)+Q_{0}^{*} e^{\left(g_{Q}-k_{Q}\right) m}-\tau_{g} Q_{0}^{*}\left(e^{-y_{Q}^{*} m} N[d 1]-e^{-r m} N[d 2]\right) \\
& =\frac{P V D_{Q}(0, m)}{1-e^{\left(g_{Q}-k_{Q}\right) m}+\tau_{g}\left(e^{-y_{Q}^{*} m} N[d 1]-e^{-r m} N[d 2]\right)} \\
& =\frac{g o r d o n_{Q}\left(1-e^{\left(g_{Q}-k_{Q}\right) m}\right)}{1-e^{\left(g_{Q}-k_{Q}\right) m}+\tau_{g}\left(e^{-y_{Q}^{*} m} N[d 1]-e^{-r m} N[d 2]\right)}
\end{aligned}
$$




$$
\begin{aligned}
& d 1=\frac{\ln \left(Q_{0}^{*} / Q_{0}^{*}\right)+\left(r-y_{Q}^{*}+\frac{1}{2} \sigma_{Q}^{2}\right) m}{\sigma_{Q} \sqrt{m}}=\frac{\left(r-y_{Q}^{*}+\frac{1}{2} \sigma_{Q}^{2}\right) m}{\sigma_{Q} \sqrt{m}} \\
& d 2=d 1-\sigma_{Q} \sqrt{m} ; \quad y_{Q}^{*}=\frac{d i v_{Q}\left(1-\tau_{d}\right)}{Q_{0}^{*}} .
\end{aligned}
$$

Note that $e^{-y_{Q}^{*} m} N[d 1]-e^{-r m} N[d 2]$ is equivalent to the value of a call option priced according to the Black-Scholes (1973) model as adjusted for dividends by Merton (1973b), assuming an initial stock price and striking price of $\$ 1$.

In equation (10), $Q_{0}^{*}$ is embedded in $e^{-y_{Q}^{*} m}$ and $d 1$, both of which appear on the right-hand side of the equation. Unfortunately, we are unable to solve for $Q_{0}^{*}$ directly. Therefore, we employ binary search to solve for the value of $Q_{0}^{*}$, which equates the left and right hand sides of equation (10). This equilibrium solution value for the portfolio establishes its after-tax dividend yield, $y_{Q}^{*}$. With this dividend yield, the equilibrium value of the stock becomes:

$$
\begin{aligned}
& S_{0}^{*}=\frac{\operatorname{gordon}_{S}\left(1-e^{\left(g_{S}-k_{S}\right) m}\right)}{1-e^{\left(g_{S}-k_{S}\right) m}+\tau_{g}\left(e^{-y_{S}^{*} m} N[x 1]-e^{-r m} N[x 2]\right)} \\
& x 1=\frac{\left(r-y_{Q}^{*}-\frac{1}{2} \sigma_{Q}^{2}+\rho \sigma_{Q} \sigma_{S}\right) m}{\sigma_{Q} \sqrt{m}} ; \quad x 2=\frac{\left(r-y_{Q}^{*}-\frac{1}{2} \sigma_{Q}^{2}\right) m}{\sigma_{Q} \sqrt{m}} ; \\
& y_{S}^{*}=\frac{\operatorname{div}_{S}\left(1-\tau_{d}\right)}{S_{0}^{*}} ; \quad \text { gordon }_{S}=\frac{d i v_{S}\left(1-\tau_{d}\right)}{k_{S}-g_{S}} .
\end{aligned}
$$

As in the valuation of the market portfolio, where $Q_{0}^{*}$ appears on both sides of equation (10), $S_{0}^{*}$ appears on both sides of equation (11), and we are unable to obtain a direct solution for $S_{0}^{*}$. Nevertheless, using binary search we are able to determine the value of $S_{0}^{*}$ that satisfies both sides of equation (11) to any desired degree of accuracy.

The impact of the correlation of the stock's returns with the portfolio returns in the stock's valuation is the primary focus of this paper. Correlation affects firm value in two ways. The first is the straightforward effect through $x 1$, where firms with low correlation benefit from 
the pooling of gains and losses. The second is through the firm's required return. Specifically, we assume that a Continuous Time Capital Asset Pricing Model-based risk-return relationship is embedded in the equilibrium stock price $S_{0}^{*}$. According to the Continuous Time CAPM (Merton [1973a]), $k_{S}=r+\beta_{S, Q}\left(k_{Q}-r\right)=r+\frac{\rho \sigma_{S}}{\sigma_{Q}}\left(k_{Q}-r\right)$, where $\beta_{S, Q}$ is the instantaneous beta of the stock in relation to the market portfolio. (Technically, as shown in the appendix, $\beta_{S, Q}$ is what the stock's beta would be if capital gains were not subject to taxation.) Therefore, for the purposes of computing $S_{0}^{*}, k_{S}=r+\frac{\rho \sigma_{S}}{\sigma_{Q}}\left(k_{Q}-r\right)$. A justification for assuming $k_{S}=r+\frac{\rho \sigma_{S}}{\sigma_{Q}}\left(k_{Q}-r\right)$ is provided in the appendix.

\section{Model Properties}

\section{A. Conditions for no capital gains tax effect in valuation}

An examination of equation (11) shows that the model price for the stock will be the same as its corresponding Gordon value, and, therefore, will not reflect the potential for capital gains taxation, if the term $\tau_{g}\left(e^{-y_{S}^{*} m} N[x 1]-e^{-r m} N[x 2]\right)$ equals zero. This will be the case if the capital gains tax rate, $\tau_{g}$, equals zero or if $e^{-y_{S}^{*} m} N[x 1]=e^{-r m} N[x 2]$. Clearly, if $\tau_{g}=0$, capital gains taxation can have no effect on the value of the stock. But even if $\tau_{g}>0$, the potential to net portfolio capital gains and losses can eliminate any capital gains tax-related impact in the valuation of the stock if $e^{-y_{S}^{*} m} N[x 1]=e^{-r m} N[x 2]$.

To understand the conditions for which $e^{-y_{S}^{*} m} N[x 1]=e^{-r m} N[x 2]$, note that $x 1=\frac{\left(r-y_{Q}^{*}-\frac{1}{2} \sigma_{Q}^{2}+\rho \sigma_{Q} \sigma_{S}\right) m}{\sigma_{Q} \sqrt{m}}$ and $x 2=\frac{\left(r-y_{Q}^{*}-\frac{1}{2} \sigma_{Q}^{2}\right) m}{\sigma_{Q} \sqrt{m}} . x 1$ and $x 2$ will be equal, and, therefore, $N(x 1)$ and $N(x 2)$ will also be equal, if $\rho=0$. But with $\rho=0$ and $N(x 1)=N\left(x_{2}\right)$, the entire capital gains valuation effect as given by $\tau_{g}\left(e^{-y_{S}^{*} m} N[x 1]-e^{-r m} N[x 2]\right)$ will equal zero only if $y_{S}^{*}=r$. 
If capital gains taxation has no effect in valuation, the stock's price will equal that of the Gordon model, or $S_{0}^{*}=\frac{d i v_{S}\left(1-\tau_{d}\right)}{k_{S}-g_{S}}$. Moreover, if the CAPM governs the required return applicable to the stock's expected dividend stream, such that $k_{S}=r+\frac{\rho \sigma_{S}}{\sigma_{Q}}\left(k_{Q}-r\right)$, the stock's Gordon value will be $S_{0}^{*}=\frac{d i v_{S}\left(1-\tau_{d}\right)}{r+\frac{\rho \sigma_{S}}{\sigma_{Q}}\left(k_{Q}-r\right)-g_{S}}$. Recognizing that $y_{S}^{*}=\frac{d i v_{S}\left(1-\tau_{d}\right)}{S_{0}^{*}}$, the Gordon model implies the following relationship among the required return, dividend yield and rate of dividend growth: $r+\frac{\rho \sigma_{S}}{\sigma_{Q}}\left(k_{Q}-r\right)=y_{S}^{*}+g_{S}$. With $\rho=0$, this relationship simplifies to $r=y_{S}^{*}+g_{S}$. Thus, if $\rho=0$ and $g_{S}=0, y_{S}^{*}$ will equal $r$, causing $\tau_{g}\left(e^{-y_{s}^{*} m} N[x 1]-e^{-r m} N[x 2]\right)=0$, and there will be no capital gains tax effect in the pricing of the stock. $^{13}$

This is an intuitively appealing result. If $\rho=0$, any capital gains resulting from random movements in the stock's price should be neutralized by other realized gains and losses in the larger market portfolio. However, capital gains can also occur for the stock on a non-random basis if the expected growth rate in dividends, $g_{S}$, exceeds zero. With $g_{S}>0$, both the level of dividend payment and the level of the stock's price would be expected to increase over time. Thus, even if $\rho=0$, and all potential capital gains taxation from random stock price movements is expected to be neutralized, if $g_{S}>0$, the expectation of a natural increase in the price of the stock should cause the potential for capital gains taxation to be reflected in the stock price. Therefore, to neutralize the effects of capital gains taxation when $g_{S}>0, \rho$ must be negative.

If $\rho<0$, the stock should be priced as if there will be negative taxation of randomly generated capital gains. With $\rho<0$, if there is a gain in the value of the market portfolio, there is likely to be a loss in the value of the stock. In this case, the stock's loss can be offset against the overall gain, which, in turn, would result in an incremental negative capital gains tax for the stock. On the other hand, if there is a realized loss in the market portfolio, there is likely to be a

\footnotetext{
${ }^{13}$ Implicitly, this analysis requires $r>0$. Otherwise, $g_{S}>k_{S}$, and the stock's Gordon value will be undefined.
} 
gain in the stock. But since no tax would be paid at the portfolio level, the incremental tax associated with the stock's gain would be zero. Therefore, in an expected value sense, with $\rho<0$, the stock should be priced as if there will be a negative tax associated with randomly generated capital gains.

\section{B. General Effect of Capital Gains Taxation in Stock Valuation}

Table I summarizes the general effect of capital gains taxation in the valuation of the stock as a function of the correlation of stock and portfolio returns, $\rho$, and the growth rate in the stock's dividend, $g_{S}$. Figure 1 provides a graphical representation of the joint effect of correlation and dividend growth on the model value of the stock as a proportion of its Gordon value, assuming capital gains are taxed at a rate of 20 percent as they are today.

\begin{tabular}{|c|c|c|c|}
\hline \multicolumn{4}{|c|}{ Table I } \\
\multicolumn{4}{|c|}{$\begin{array}{c}\text { Effect of correlation, } \rho \text {, and dividend growth, } g_{S} \text {, on the } \\
\text { equilibrium value of stock in relation to Gordon value }\end{array}$} \\
\hline & $\rho<0$ & $\rho=0$ & $\rho>0$ \\
\hline$g_{S}<0$ & $S_{0}^{*}>$ gordon $_{S}$ & $S_{0}^{*}>$ gordon $_{S}$ & $\begin{array}{l}\text { Relationship depends } \\
\text { on specific value of } \rho\end{array}$ \\
\hline$g_{S}=0$ & $S_{0}^{*}>$ gordon $_{S}$ & $S_{0}^{*}=$ gordon $_{S}$ & $S_{0}^{*}<$ gordon $_{S}$ \\
\hline$g_{S}>0$ & $\begin{array}{l}\text { Relationship depends } \\
\text { on specific value of } \rho\end{array}$ & $S_{0}^{*}<$ gordon $_{S}$ & $S_{0}^{*}<$ gordon $_{S}$ \\
\hline
\end{tabular}

The relationships summarized in table I are evident in figure $1 .{ }^{14}$ Generally, if both the growth rate in dividends and the correlation between stock and market returns are positive, conditions that should hold for most exchange-traded stocks, the potential taxation of capital gains should have a negative impact on the pricing of the stock. However, it is possible for the valuation impact of capital gains taxation to be positive for an individual stock if correlation is negative and / or, if dividends, and, hence, the price of the stock itself, are projected to decrease in value over time.

\footnotetext{
${ }^{14}$ In figure 1, the following parameter values are assumed: $\tau_{g}=0.20, r=0.05, k_{Q}=0.10 g_{Q}=0.02, \sigma_{Q}=0.18$, $\sigma_{S}=0.30$. It can be shown that higher values of $k_{Q}$ tend to steepen the curves in Figure 1 . Higher values of $g_{Q}$ tend to shift the point at which the three curves converge to the left.
} 
Figure 1 shows that correlation also affects the stock's required return through the CAPM-based relationship, $k_{S}=r+\frac{\rho \sigma_{S}}{\sigma_{Q}}\left(k_{Q}-r\right)$, or $k_{S}=0.05+\rho\left(\frac{0.30}{0.18}\right)(0.10-0.05)$ in this particular example. With negative correlation, the stock's required return will be relatively low, causing any positive valuation effect from capital gains taxation to be magnified even further. On the other hand, large positive values of $\rho$ are associated with higher required returns, which, in turn, partially mitigate the negative impact of capital gains taxation in the valuation of the stock.

Figure 1 also illustrates how the selling horizon, $m$, affects the value of $S_{0}^{*} /$ gordon $_{S}$. For the one-year selling horizon, the relationship between $S_{0}^{*} /$ gordon $_{S}$ and the correlation coefficient, $\rho$, is steeper in comparison to that for the five-year horizon. Interestingly, even for a selling horizon as short as five years, capital gains taxation has very little impact in valuation when $\rho>0$. At the extreme, when $\rho=1$ and $m=5$, the values of $S_{0}^{*} /$ gordon $_{S}$ for stock growth rates of $-0.02,0.0$ and 0.02 are $0.989,0.978$, and 0.964 , respectively. If there were no tax impact, all three values would equal 1.0.

Figure 2 provides more detail on the relationship between $S_{0}^{*} /$ gordon $_{S}$ and the selling horizon, $m$, and illustrates that for any rational set of parameter values, such that $k_{S}>g_{S}$, $\lim _{m \rightarrow 0} S_{0}^{*} /$ gordon $_{S}=0$ if $\rho>0, \lim _{m \rightarrow 0} S_{0}^{*} /$ gordon $_{S}=\infty$ if $\rho<0$, and $\lim _{m \rightarrow \infty} S_{0}^{*} /$ gordon $_{S}=1$ for all values of $\rho$. It also illustrates that for selling horizons of two or more years, the relationship between $S_{0}^{*} / \operatorname{gordon}_{S}$ and $m$ is relatively flat; there is little difference between $S_{0}^{*} /$ gordon $_{S}$ for a selling horizon of two years and that associated with a much longer selling horizon. However, for horizons less than two years, and especially less than one year, the relationship between $S_{0}^{*} / \operatorname{gordon}_{S}$ and $m$ becomes much steeper. With very short selling horizons, negative correlation becomes infinitely valuable, while positive correlation drives stock value to zero. C. Sensitivity of Price to a Change in the Capital Gains Tax Rate

This section explores the extent to which the equilibrium stock price is affected by a change in the capital gains tax rate. To examine this effect, the derivative of the equilibrium stock price with respect to a change in the capital gains tax rate is estimated numerically by 
computing the difference between the equilibrium stock price evaluated at $\tau_{g}+0.001$ and $\tau_{g}-0.001$ and dividing the difference by 0.002 . This derivative indicates how many dollars the stock price should change per unit change in the tax rate. It is more useful, however, to express this change as a proportion of the stock price, $\frac{d S_{0}^{*} / S_{0}^{*}}{d \tau_{g}}$. In this form, $\frac{d S_{0}^{*} / S_{0}^{*}}{d \tau_{g}}$ can be interpreted as the return of the stock per unit change in the capital gains tax rate. It is important to note that a one percentage point change in the tax rate, for example, from 0.20 to 0.21 , represents a change of 0.01 units, not one unit. Thus, a one percentage point increase in the tax rate should be accompanied by a stock return of approximately $\left(\frac{d S_{0}^{*} / S_{0}^{*}}{d \tau_{g}}\right)(0.01)$.

The four panels of figure 3 illustrate the functional relationship between $\frac{d S_{0}^{*} / S_{0}^{*}}{d \tau_{g}}$ and the correlation between stock and market returns, the expected return of the overall portfolio, $k_{Q}$, the selling horizon, $m$, and the growth rate in dividends, $g_{S}$. In figure 3 , the capital gains tax rate is assumed to be 0.28 , the Federal tax rate in effect prior to the reduction in 1997 to 0.20 . Other parameter values assumed in all panels of the figure are $r=0.05, g_{Q}=0.02, \sigma_{Q}=0.18$ and $\sigma_{S}=0.30$. In the upper portion of figure 3 , the expected market return, $k_{Q}$, is assumed to be 0.10 , which implies a market risk premium of $k_{Q}-r=0.10-0.05=0.05$. In the lower portion, $k_{Q}=r=0.05$, consistent with no risk premium. The two panels on the left are associated with a selling horizon of one year while the two panels on the right are associated with a five-year horizon.

Several relationships are evident from the four panels. For stocks whose returns are positively correlated with those of the market portfolio, the proportional change in price resulting from a change in the capital gains tax rate is less negative for the longer five-year selling horizon. For stocks with positive correlation, return sensitivity to a change in the tax rate is much more negative when the risk premium is low (as shown in the lower portion of figure 3 where $\left.k_{Q}=r=0.05\right)$. Presumably, in a market with little risk premium, stock prices are relatively high to begin with, and, in a sense, have further to fall in percentage terms if the tax 
rate is increased. This same concept appears to apply to the relationship between $\frac{d S_{0}^{*} / S_{0}^{*}}{d \tau_{g}}$ and the growth rate in dividends, $g_{S}$. Stock prices of firms with positive correlation and higher dividend growth rates, and, hence, higher prices relative to dividends and earnings, tend to be more adversely affected by a change in the capital gains tax rate than stocks of firms with lower growth rates.

The four panels of Figure 3 suggest some interesting mathematical patterns over the negative range of correlation. With the exception of the $g_{S}=0.04$ portions of the upper panels, a point is reached in all the panels where the correlation coefficient is sufficiently negative that $\frac{d S_{0}^{*} / S_{0}^{*}}{d \tau_{g}}>0$. This implies that stocks with correlations below this level should increase in value when the capital gains tax rate goes up and decrease in value when it goes down, a result consistent with the diversification value of negative correlation discussed earlier.

Figure 4 illustrates the relationship between the proportional change in the value of the market portfolio with respect to a change in the capital gains tax rate, $\frac{d Q_{0}^{*} / Q_{0}^{*}}{d \tau_{g}}$, as a function of the selling horizon, the growth rate in dividends for the market portfolio, and the expected market return. Generally, lower values of the expected market return and higher dividend growth rates, both of which imply higher values for the market portfolio, are associated with greater sensitivity to a change in the capital gains tax rate. The values of $\frac{d Q_{0}^{*} / Q_{0}^{*}}{d \tau_{g}}$ in Figure 4 are economically significant; values on the order of $-1.5 \leq \frac{d Q_{0}^{*} / Q_{0}^{*}}{d \tau_{g}} \leq-0.5$ appear to be possible for reasonable combinations of $k_{Q}, g_{Q}$, and $m$. This would suggest that the change in the capital gains tax rate from 0.28 to 0.20 in 1997 should have been accompanied by a proportional increase in the value of the market portfolio of roughly $-1.5(0.20-0.28)=12$ percent to $-0.05(0.20-0.28)=4$ percent. These predicted returns are consistent with a 6.1 percent mean return for stocks of dividend-paying firms and 12.9 percent for non-dividend-paying firms reported by Lang and Shackelford (2000) for the five trading day period, Tuesday April 29 
through Monday, May 5, surrounding the May 2, 1997 budget agreement. Although a reduction in the capital gains tax rate was not specifically announced at that time, the business press immediately began to speculate that the capital gains tax rate would be reduced from 28 percent to between 15 and 20 percent. $^{15}$

\section{Summary}

To summarize, two stock-specific forces are at work in determining the valuation impact of the capital gains tax, both of which are related to the ability of the stock to offset portfolio gains with losses (or vice versa). If the stock is likely to incur losses when the portfolio incurs gains, the inclusion of the stock in the portfolio will have the effect of reducing the capital gains tax that would otherwise accrue to the portfolio. On the other hand, if the stock is likely to incur gains when the portfolio incurs losses, including the stock in the portfolio keeps a portion of the portfolio's potential tax loss deductions from being wasted, and enables the stock to be priced as if it is not subject to capital gains taxation. In either case, including the stock in the portfolio has the effect of reducing or eliminating capital gains taxes, and at the margin, should be value enhancing.

Stock and portfolio returns will tend to offset when they are negatively correlated. Therefore, holding other factors constant, a stock's value should increase as the correlation of its returns with portfolio returns becomes lower. Returns will also tend to offset when the growth rates in dividends for the stock and portfolio are of opposite sign. For example, when the dividend growth rate for the portfolio is positive, the value of the portfolio would be expected to grow at the same rate, and, therefore, the portfolio, on average, would be expected to produce capital gains. If the growth rate in dividends for the stock is negative, then the stock is expected to produce capital losses. Therefore, adding the stock to the portfolio should reduce capital gains taxes and, therefore, result in a positive impact in the pricing of the stock.

Two other effects are also important. First, if $k_{Q} \neq r$, the discount rate will be related to the correlation between stock and portfolio returns. Second, if the stock grows at a sufficiently rapid rate, the benefits of diversification can be overwhelmed by the capital gains taxes ultimately paid on the share's appreciation.

\footnotetext{
${ }^{15}$ For more detail about the political events and climate leading up to the tax cut, see Lang and Shackelford (2000, pp. 75-76).
} 


\section{Conclusion}

Theoretical and empirical analyses of the taxation of capital gains and losses typically ignore the fact that the marginal tax rate applied to a specific capital gain and loss depends on the total portfolio of realized capital gains and losses during the year. This paper analyzes the stock valuation implications created by this pooling.

We find that the impact of capital gains taxation on stock values can be positive or negative depending on the correlation between the stock's returns and those of the overall portfolio. The present value of capital gain taxes associated with an individual stock is generally increasing if the returns of the stock are positively correlated with the returns of the market portfolio. On the other hand, valuations for stocks whose returns are negatively correlated with market returns generally are increasing in capital gains tax rates. This consequence of the current U.S. system of taxing capital gains and losses should produce less of a tax penalty and even a premium in the pricing of stocks with low return correlation with the market.

If the extent to which portfolio netting affects current stock valuations is significant, it carries important and potentially overlooked policy implications for ongoing debates. In short, the current system of netting capital gains and losses affects individual firm valuations differently, depending on the correlation of their returns with movements in the overall stock market. As a result, the burden of the capital gains tax is not born equally by all equity shares. Some shares bear a significant portion of the overall capital gains tax burden while others can actually benefit from the taxation of capital gains. A tax whose distributional effects vary with the correlation and growth characteristics specific to individual investments, rather than the income and wealth levels of their investors, cannot be justified under conventional tax theory and is likely an unintended consequence. Policy remedies could include lifting the limitation on losses or substituting a transaction tax for the capital gains tax. 


\section{Appendix}

Why the Stock's Required Return Should be Based on the Continuous Time Capital Asset Pricing Model

We justify setting $k_{S}$ to $r+\frac{\rho \sigma_{S}}{\sigma_{Q}}\left(k_{Q}-r\right)$ on the following grounds. Consider equation 2 which breaks out the value of the stock into three components. The first component, $P V D_{S}(0, m)=\int_{0}^{m} d i v_{S}\left(1-\tau_{d}\right) e^{\left(g_{S}-k_{S}\right) t} d t$, is the present value of dividends from now (time 0$)$ until time $m$, the time at which the stock is expected to be sold. The second component, $\phi_{S} P V D_{S}(0, m) e^{\left(g_{S}-k_{S}\right) m}$, is the stock's expected selling price as of time $m$ discounted to the present at the rate $k_{S}$. The third component, $\tau_{g} P V\left(\left[\widetilde{S}_{m}-B_{S}\right] \mid \widetilde{Q}_{m}>B_{Q}\right)$, is the present value of capital gains taxes expected to be incurred in connection with the sale of the stock at time $m$.

Note that the required return, $k_{S}$, enters the first two terms but not the third. If it were not for the third term, the required return, $k_{S}$, would be that which is appropriate for valuing the stock in the absence of capital gains taxation. Given the assumption of a lognormal stock price, if there were no capital gains taxation, Merton's (1973a) continuous time Capital Asset Pricing Model would provide the appropriate required return for determining both $P V D_{S}(0, m)$, the present value of dividends from time zero to time $m$, and $\phi_{S} P V D_{S}(0, m) e^{\left(g_{S}-k_{S}\right) m}$, the present value of the stock price expected at time $m$.

As Modigliani and Miller (1963) show in their classic paper on the effects of the corporate interest tax deduction on the value of a firm, the value of a levered firm equals the value of the same firm if it were unlevered plus the present value of taxes saved through the interest deduction. In determining unlevered value, the firm's expected unlevered after-tax cash flow is discounted at an unlevered cost of capital - that is, the rate that should apply to the valuation of after-tax expected cash flow if the firm had no debt. A separate capitalization rate is then applied to the taxes saved through the interest deduction. The notion of separating a firm's cash flows into components with different tax and risk characteristics and valuing the components separately has come to be known as the "value additivity principle." 
This same principle should apply to the valuation of the components of a stock's value. Together, the first two components of equation 2 represent what the total value of the stock would be in the absence of capital gains taxation. As in Modigliani and Miller, these component values should be determined as if there were no capital gain tax. The third term in equation 2 reflects the effects of capital gains taxation on firm value, just as the second term in Modigliani and Miller's valuation equation reflects the value of corporate taxes saved from deducting interest. Thus, by assuming $k_{S}$ is determined by Merton's Continuous Time Capital Asset Pricing Model, we are simply invoking the value additivity principle.

Consistent with Modigliani and Miller (1963) and the value additivity principle, $k_{S}$ should be interpreted as the stock's required (or instantaneous expected) return in the absence of capital gains taxation, and $k_{Q}$ should be interpreted as the required market return in the absence of capital gains taxation. Similarly, $\beta_{S, Q}=\frac{\rho \sigma_{S}}{\sigma_{Q}}$ and its components $\rho, \sigma_{S}$, and $\sigma_{Q}$, should be interpreted as statistical parameters estimated in the absence of capital gains taxation. Together, these parameters imply an un-taxed required return, $k_{S}=r+\frac{\rho \sigma_{S}}{\sigma_{Q}}\left(k_{Q}-r\right)$, which should be interpreted in the same way as Modigliani and Miller's unlevered cost of capital. 


\section{References}

Auerbach, A., L. Burman, and J. Siegel. "Capital Gains Taxation and Tax Avoidance: New Evidence from Panel Data In Does Atlas Shrug? The Economic Consequences of Taxing the Rich, edited by J. Slemrod, pp. 355-388. New York: Russell Sage Foundation and Harvard University, 2000.

Ayes, B., C. Lefanowicz, and J. Robinson. "Shareholder Taxes in Acquisition Premiums: The Effect of Capital Gains Taxation." Journal of Finance (2003), forthcoming.

Black, F. and M. Scholes. "The Pricing of Options and Corporate Liabilities." Journal of Political Economy (1973) 81: 637-654.

Blouin, J., J. Raedy, and D. Shackelford. "Capital Gains Taxes and Equity Trading: Empirical Evidence." Journal of Accounting Research (2003), forthcoming.

Constantinides, G. “Capital Market Equilibrium with Personal Tax.” Econometrica (1983) 51: 611-636.

Constantinides, G. “Optimal Stock Trading with Personal Taxes.” Journal of Financial Economics (1984) 13: 65-89.

Erickson, M. "The Effect of Taxes on the Structure of Corporate Acquisitions." Journal of Accounting Research (1998) 36: 279-298.

Gentry, W. and R. Hubbard, "Tax Policy and Entry into Entrepreneurship." 2001. Working paper, Columbia University.

Graham, J., "Taxes and Corporate Finance: A Review." Review of Financial Studies (2003), forthcoming.

Graham, J., and C. Smith, "Tax Incentives to Hedge." Journal of Finance (1999) 54, 2241-2262.

Guenther, D., and M. Willenborg. "Capital Gains Tax Rates and the Cost of Capital for Small Business: Evidence from the IPO Market.” Journal of Financial Economics (1999) 53: 385-408.

Internal Revenue Service. "Individual Income Tax Returns, 1997." Statistics of Income Bulletin (1999a). Publication 1136.

Internal Revenue Service. "Individual Income Tax Rates and Shares, 1997." Statistics of Income Bulletin (1999b). Publication 1136.

Klein, P. "The Capital Gain Lock-in Effect and Equilibrium Returns.” Journal of Public Economics (1999) 71: 355-378. 
Landsman, W., and D. Shackelford. "The Lock-in Effect of Capital Gains Taxes: Evidence from the RJR Nabisco Leveraged Buyout.” National Tax Journal (1995) 48: 245-59.

Lang, M., and D. Shackelford. "Capitalization of Capital Gains Taxes: Evidence from Stock Price Reactions to the 1997 Rate Reductions.” Journal of Public Economics (2000) 76: 69-85.

Merton, R. C., “An Intertemporal Capital Asset Pricing Model,” Econometrica (1973a) 41: 867880.

Merton, R. C., "Theory of Rational Option Pricing," The Bell Journal of Economics and Management Science (1973b) 4: 141-183.

Modigliani, F. and M. Miller. "Corporate Income Taxes and the Cost of Capital." American Economic Review (1963): 433-443.

Poterba, J. "How Burdensome are Capital Gains Taxes?" Journal of Public Economics 33 (1987): 157-172.

Poterba, J., and S. Weisbenner. "Capital Gains Tax Rules, Tax-loss Trading, and Turn-of-theyear Returns.” Journal of Finance (2001) 56: 353 - 368.

Reese, W. "Capital Gains Taxation and Stock Market Activity: Evidence from IPOs.” Journal of Finance (1998) 53: 1799-1820.

Rubinstein, M., "The Valuation of Uncertain Income Streams and the Pricing of Options, ” Bell Journal of Economics (1976) 7: 407-425.

Shackelford, D. "Stock Market Reaction to Capital Gains Tax Changes: Empirical Evidence from the 1997 and 1998 Tax Acts." In Tax Policy and the Economy. Vol. 14, edited by J. Poterba, pp. 67-92. Cambridge, MA: National Bureau of Economic Research and MIT Press, 2000.

Shackelford, D. and T. Shevlin. "Empirical Tax Research in Accounting." Journal of Accounting and Economics (2001) 31: 1-67.

Shackelford, D., and R. Verrecchia. "Intertemporal Tax Discontinuities.” Journal of Accounting Research 40:1, March 2002, 205-222.

Stiglitz, J. "Some Aspects of the Taxation of Capital Gains." Journal of Public Economics (1983) 21: 257-294.

Stulz, R.M., "Options on the Minimum or the Maximum of Two Risky Assets: Analysis and Applications," Journal of Financial Economics (1982) 10: 161-185. 
Stock sold every year $(m=1)$

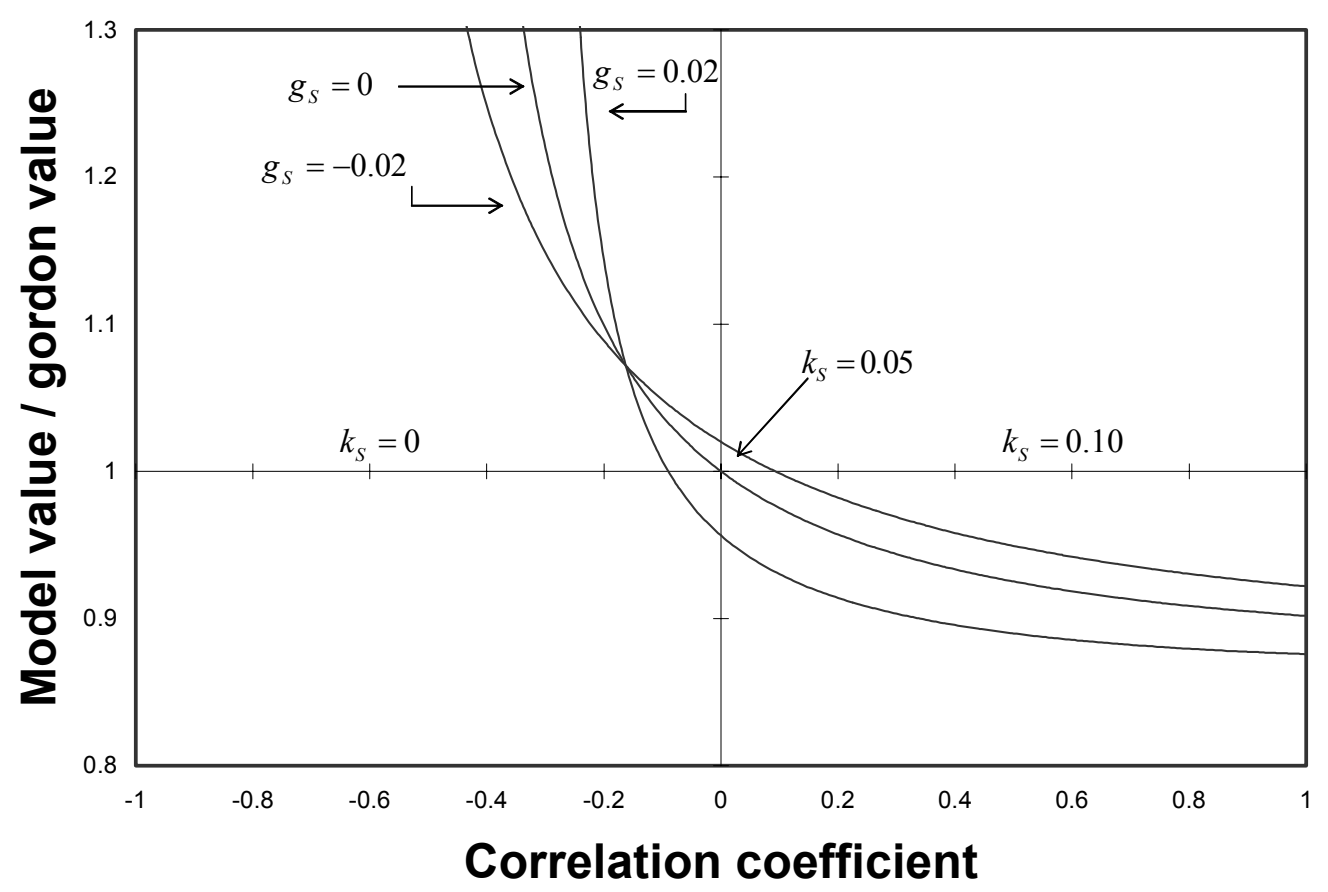

Stock sold every 5 years $(m=5)$

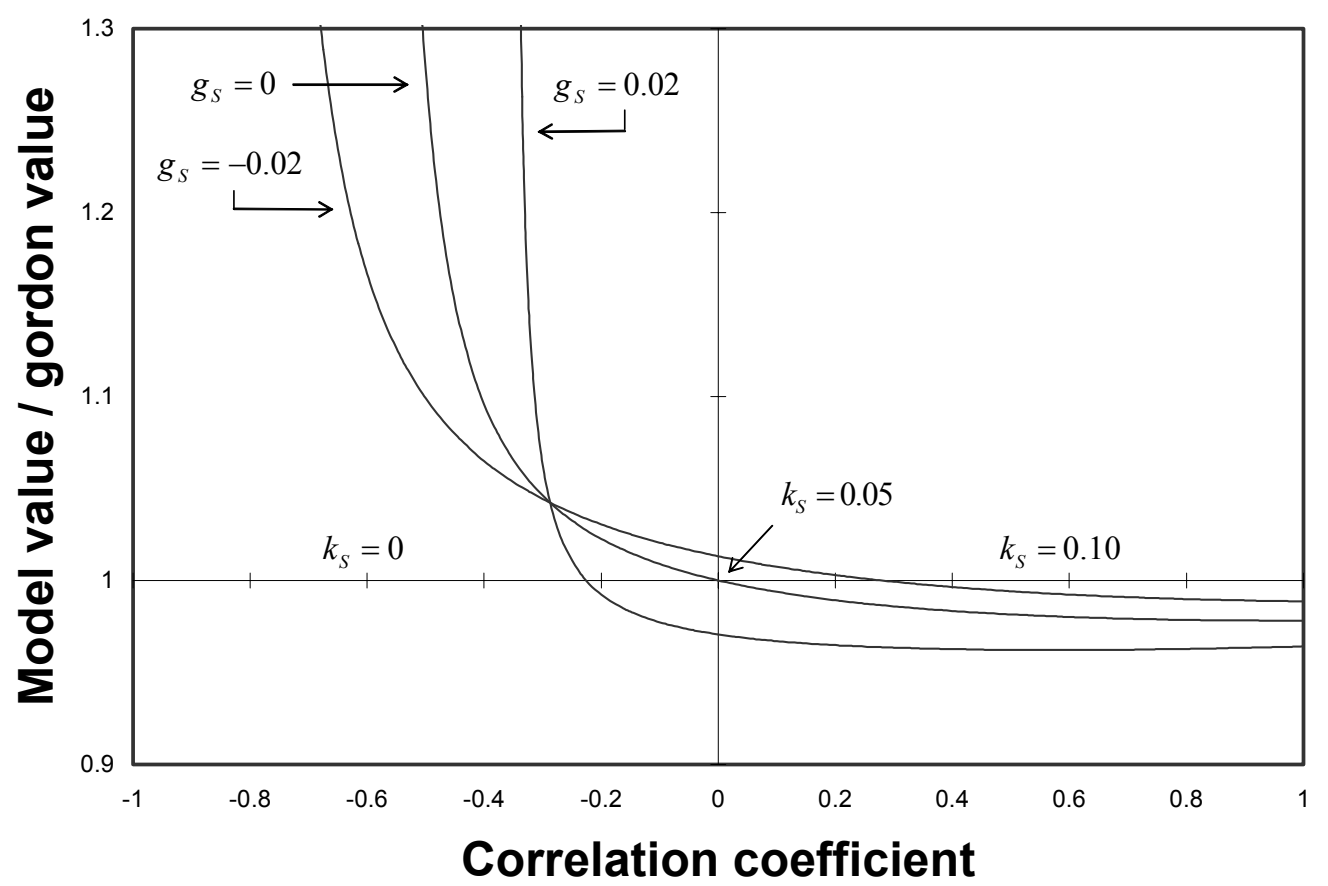

Figure 1. $S_{0}^{*} /$ gordon $_{S}$ as a function of the correlation between stock and market returns and the growth rate in dividends, $g_{s}$. Parameter values: $\tau_{g}=0.20, r=0.05, k_{Q}=0.10 g_{Q}=0.02, \sigma_{Q}=0.18$, $\sigma_{s}=0.30$. 

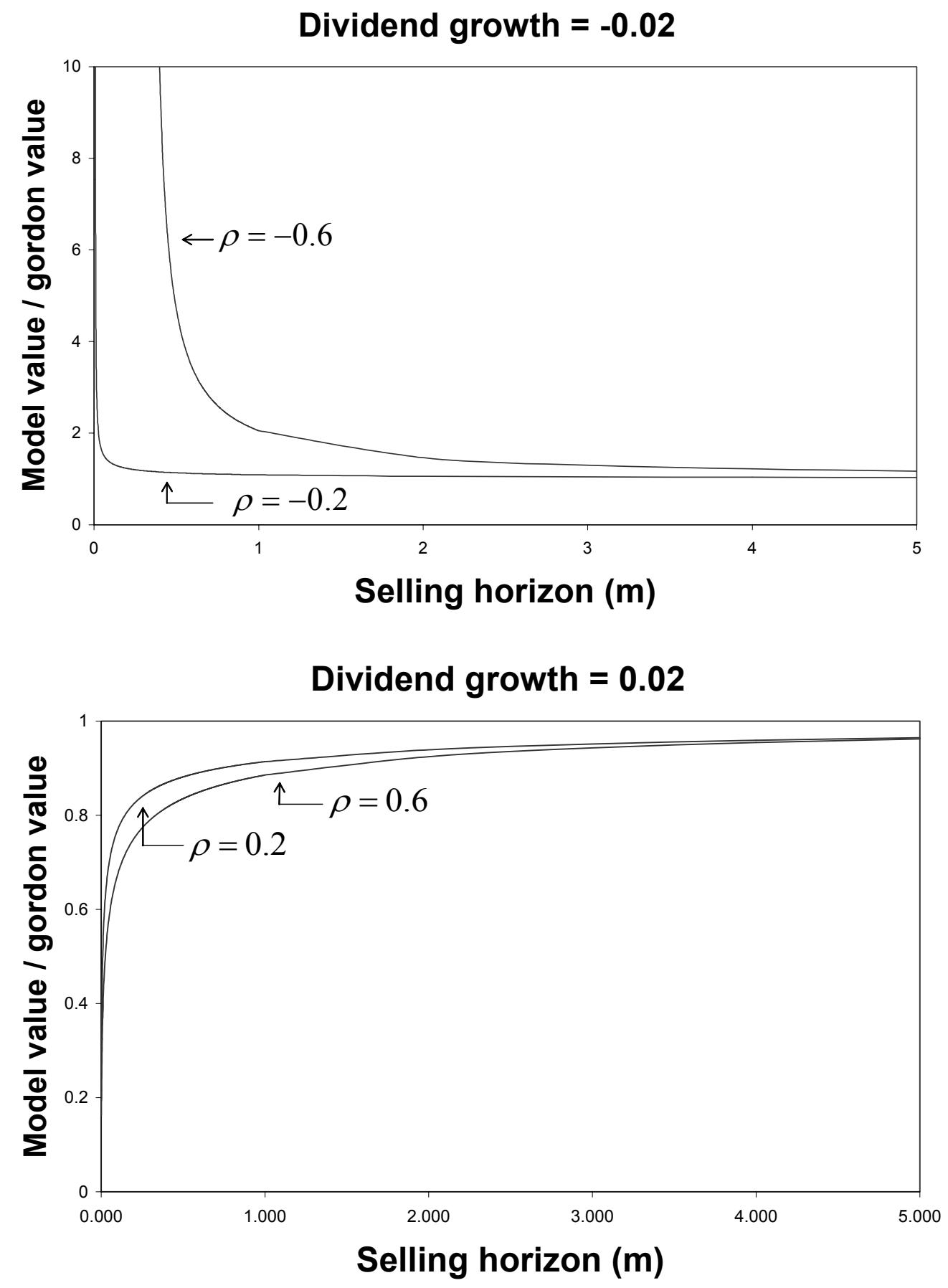

Figure 2. $S_{0}^{*} /$ gordon $_{S}$ as a function of the selling horizon, $m$, and the correlation between stock and market returns. Parameter values: $\tau_{g}=0.20, r=0.05, k_{Q}=0.10 g_{Q}=0.02, \sigma_{Q}=0.18, \sigma_{s}=0.30$. A negative dividend growth rate is assumed in the upper panel to prevent $k_{S} \leq g_{S}$. With $\rho=-0.6$, $k_{S}=0.05+(-0.6)\left(\frac{0.30}{0.18}\right)(0.10-0.05)=0>-0.02$, and with $\rho=-0.2, k_{S}=0.0333>-0.02$. 


$$
k_{Q}=0.10
$$

Selling horizon $=1$ year

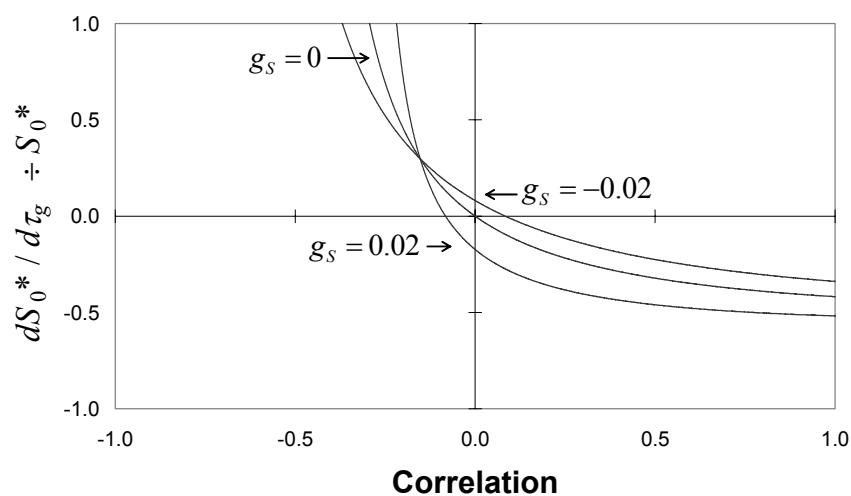

Selling horizon $=\mathbf{5}$ years

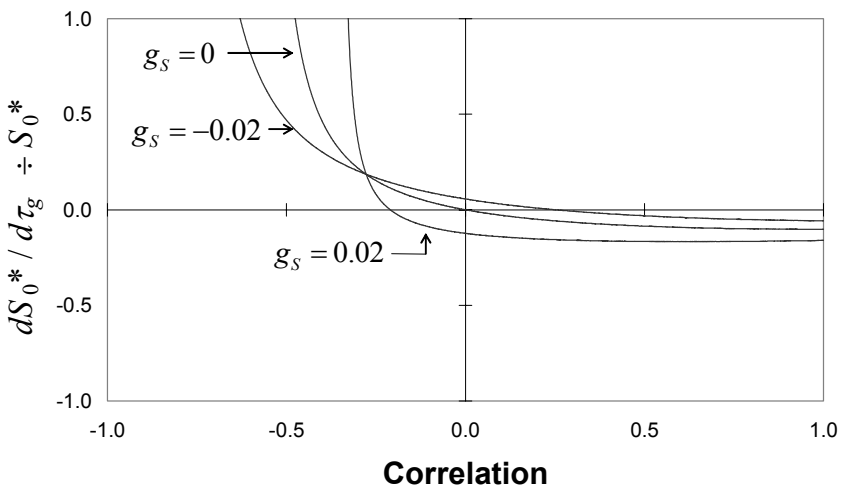

$$
k_{Q}=r=0.05
$$

Selling horizon $=\mathbf{5}$ years

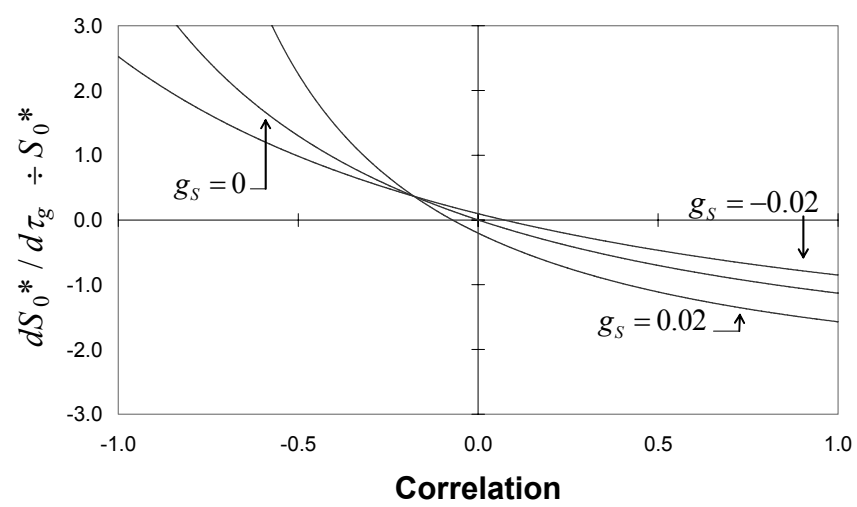

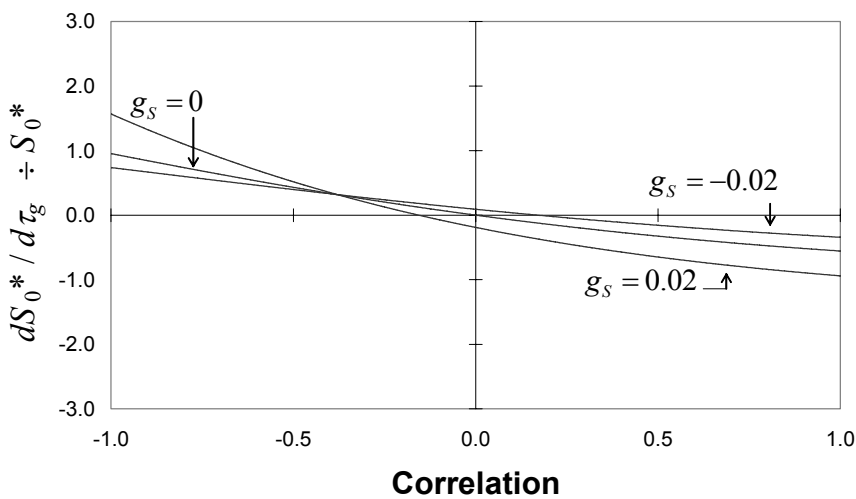

Figure 3. $\frac{d S_{0}^{*} / S_{0}^{*}}{d \tau_{g}}$ as a function of the correlation between stock and market returns, the expected return of the market portfolio, $k_{Q}$, the selling horizon, $m$, and the growth rate in dividends, $g_{s}$. Parameter values: $\tau_{g}=0.28, r=0.05, g_{Q}=0.02, \sigma_{Q}=0.18$, $\sigma_{s}=0.30$. 


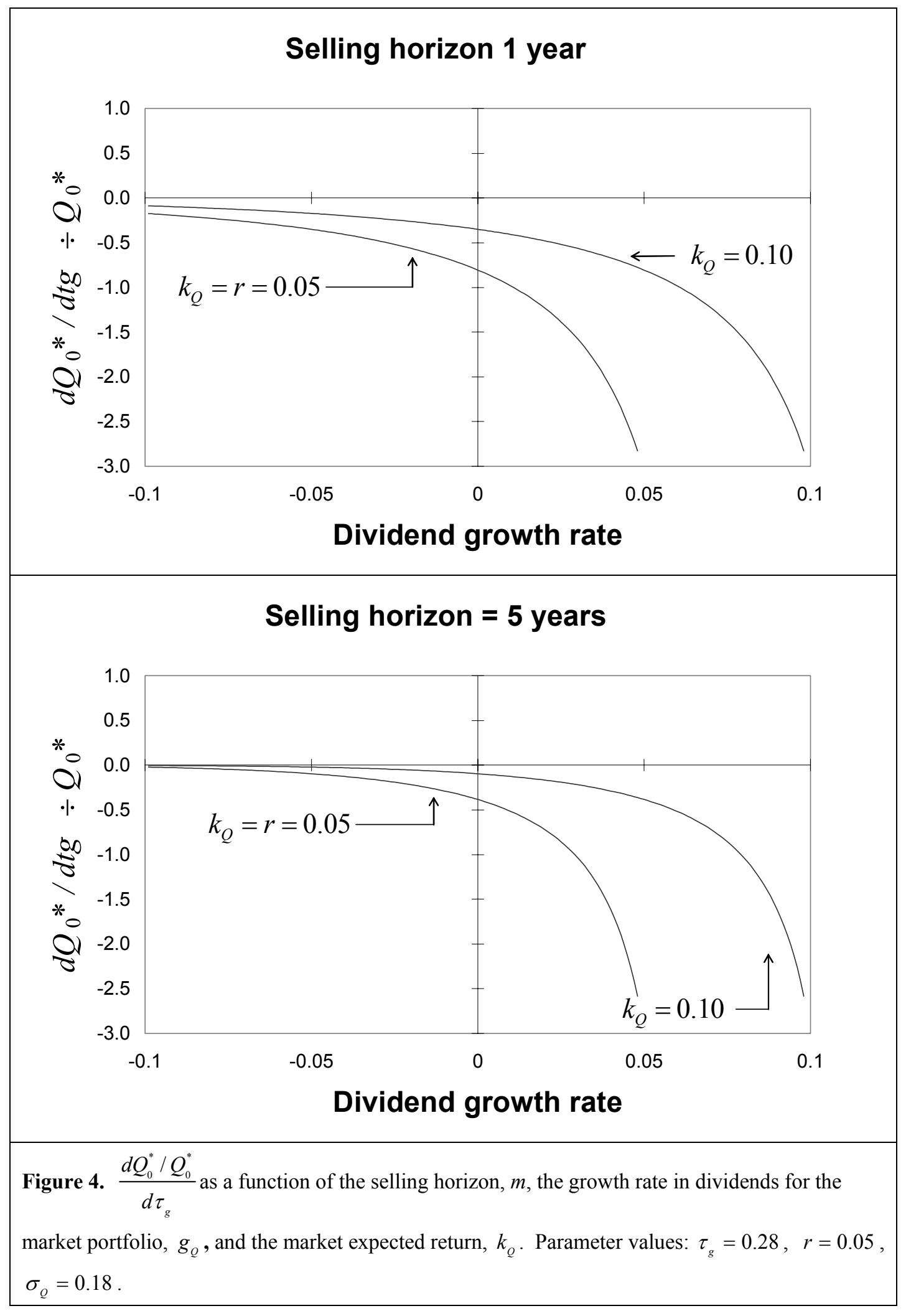

